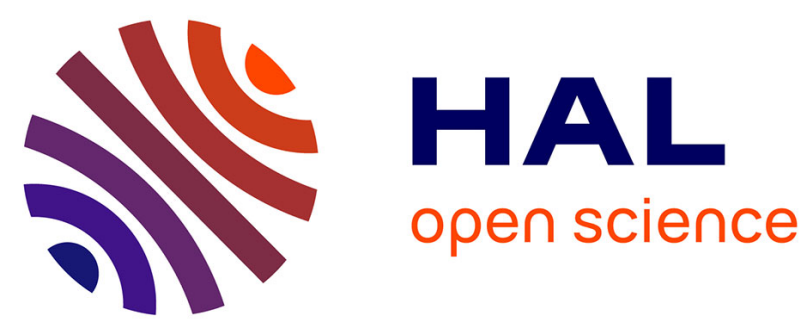

\title{
What is the nature of the reach-and-grasp deficit in glaucoma?
}

Xavier Corveleyn, Quentin Lenoble, Jean Francois Rouland, Muriel Boucart

\section{To cite this version:}

Xavier Corveleyn, Quentin Lenoble, Jean Francois Rouland, Muriel Boucart. What is the nature of the reach-and-grasp deficit in glaucoma?. Journal of Glaucoma, 2020, 10.1097/IJG.0000000000001555 . hal-03018722

\section{HAL Id: hal-03018722 \\ https://cnrs.hal.science/hal-03018722}

Submitted on 23 Nov 2020

HAL is a multi-disciplinary open access archive for the deposit and dissemination of scientific research documents, whether they are published or not. The documents may come from teaching and research institutions in France or abroad, or from public or private research centers.
L'archive ouverte pluridisciplinaire HAL, est destinée au dépôt et à la diffusion de documents scientifiques de niveau recherche, publiés ou non, émanant des établissements d'enseignement et de recherche français ou étrangers, des laboratoires publics ou privés. 
2 Xavier Corveleyn

3 Quentin Lenoble

4 Jean-François Rouland

5 Muriel Boucart

What is the nature of the reach-and-grasp deficit in glaucoma?

7

8

1. Université Côte d'Azur, LAPCOS, EA 7278, Nice, France

2. MSHS Sud-Est - Maison des Sciences de l'Homme et de la Société Sud-Est

3. Univ. Lille, CNRS, CHU Lille, UMR 9193 - SCALab - Sciences Cognitives et Sciences Affectives, F-59000, Lille, France

4. Univ. Lille, Inserm, CHU Lille, U1172 - LilNCog - Lille Neuroscience \& Cognition, F-59000 Lille, France

5. Centre Hospitalier Universitaire de Lille, Hôpital Huriez, service d'ophtalmologie, Lille, France

Figures: 5

Tables: 5

\section{Corresponding Author:}

xavier.corveleyn@univ-cotedazur.fr

Laboratoire d'Anthropologie et de Psychologie Cognitives et Sociales

Campus Saint Jean d'Angely / SJA3 / MSHS Sud-Est

3, Bd François Mitterrand

06357 Nice Cedex 4 
31 Funding : Société Française du Glaucome, 2015 (SFG)

\section{Précis}

In a reach-and-grasp task, patients with glaucoma exhibited a motor disorder, even when they had time to explore their environment. The motor performance of glaucoma patients should be taken into account in rehabilitation.

Abstract

Purpose: Vision plays an important role in planning and executing manual prehension (reaching and grasping). We assess the impact of glaucoma on motor production, as a function of the visual exploration time available to the patients.

Methods: We compared performance in two reach and grasp tasks determined by whether or not the participants (16 glaucoma patients, 14 age-matched and 18 young controls) had time to explore the objects before reaching and grasping a target object defined by its color.

Results: Differences were observed between glaucoma patients and age-matched controls on movement duration and peak velocity (reaching phase) only when participants were not provided time to look at the objects before the movement (immediate condition).

Conclusions: Glaucoma patients exhibited a motor disorder (grasping phase) only when they had no time to explore their environment before performing the reach-and-grasp task. The motor abnormalities in reaching phase observed in glaucoma patient in previous studies seem to result from difficulties in target identification rather than from visuo-motor deficits. From a clinical point of view, motor performances of glaucoma patients could be modulated by task, especially by temporal constraints of task.

\section{Key Words}




\section{Introduction}

Glaucoma is an ocular disease that produces irreversible retinal ganglion cell and optic nerve fiber loss. ${ }^{1}$ Visual deficit in glaucoma starts in the peripheral visual field and progresses towards the center. Most studies of glaucomatous vision loss assess relatively simple aspects of visual processing that are encoded in the retina (e.g. sensitivity to luminance increments as in typical perimetry or flickering gratings as in frequency-doubling technology perimetry), because glaucoma is considered primarily as a retinal ganglion cell disease. ${ }^{2,3}$ Several studies have reported that advanced glaucoma also leads to difficulties with daily life activities such as driving, fear of falling and reading, and the feeling of a reduced quality of life. ${ }^{4-6}$ Indeed, both peripheral ${ }^{7,8}$, and central vision are needed for activities such as reading, ${ }^{9,10}$ driving, facial recognition, ${ }^{11}$ reaching for and grasping objects ${ }^{12,13}$ or accomplishing natural actions. ${ }^{5}$ In the case of motor action, the visual system provides critical information about the location, size, and shape of to-be-grasped objects which is used for planning the action. The activation of the motor command leads to hand acceleration towards the object (the "reach" phase). When approaching the object, the hand decelerates and the grip aperture is adapted to the object's size (the "grasp" phase). At this phase, vision provides corrective information to

73 improve the grasp. ${ }^{14-18}$ A visual deficit can disrupt the performance of a voluntary motor 74 action, as shown in previous studies. ${ }^{12,13,19}$ For instance, some studies have shown impairments in initial movement planning and control in patients with glaucoma ${ }^{20}$ and in agerelated macular degeneration, ${ }^{12,13}$ or in grasping components in patients with amblyopia. ${ }^{21}$ Kotecha et al. (2009) reported atypical kinematic characteristics in patients with glaucoma compared to normally sighted people: slower reaction time, longer overall movement duration, low-velocity phase (suggesting a deficit in the grasping phase). The same results 
were found when healthy participants performed reach-and-grasp tasks with an artificially reduced visual field: longer overall movement duration, slower maximum velocity and higher maximum grip aperture. ${ }^{7}$

However, research on motor control suggests the existence of inverse models. ${ }^{22,23}$

These inverse models suggest that planning of motor commands requires processing of all relevant sensory information. Once the motor command is executed, the motor action can achieve its objective without visual feedback even if, for control subjects, movements are more accurate and precise when visual feedback is available. ${ }^{24}$ In line with these models, we hypothesize that increased time to explore a scene may result in decreased difficulty with a motor action for glaucoma patients. In other words, deficits in the motor performance of patients with visual impairment that have been reported in previous studies ${ }^{20}$ might be due to the fact that they were not given enough time to analyze the environment prior to motor production rather than the result of motor system deficits itself. Indeed, in these studies, participants were presented with the target object at the very moment they had to grasp it, while in daily life, patients have time to look at an object before grasping it. Therefore, laboratory studies mix two components: (1) the effect of central visual impairment on motor production and (2) the effect of visual impairment on the time for perception of the spatial properties of the object (e.g., spatial location, distance and width), leading to a deficit in motor production. This distinction is important. For instance, motor production deficits in patients with age-related macular degeneration (AMD) seem due to visual impairment, not to motor production itself. ${ }^{25}$ Therefore, patients with AMD just need more time to accomplish their daily life actions ${ }^{26}$ instead of actual rehabilitation of their motor system production. In the present study, we assess the impact of glaucoma on the two components. The kinematics of the reach-and-grasp motor action was compared in two different conditions: one in which participants saw the object only at the moment they had to grasp it, thus measuring the effect 
of a deficit in the analysis of the object's metrics on motor production, (i.e., with temporal

106 constraints for visual exploration); and one in which they had time to observe the object

107 before grasping it, thus measuring the effect of visual impairment on motor production (i.e.,

108 with no temporal constraints for visual exploration). We hypothesized that deficits in the

109 kinematic parameters of glaucoma patients should be observed in the task with temporal

110 constraints for visual exploration (immediate condition) rather than in the task with no

111 temporal constraints for visual exploration (delayed condition). Indeed, in the first task, the

112 participant needs to explore the environment quickly in order to initiate the action as soon as

113 possible. Therefore, owing to glaucoma, the visual information is not entirely processed and

114 the visual feedback, in order to adjust his (or her) action, is greater compared to the delayed

115 condition. In the delayed condition, the observation time before grasping the object allows the

116 planning of a motor command and the execution of the motor action at the appropriate

117 moment. Therefore, visual feedback is less important for accomplishing a motor action

118 compared to the immediate condition. We also investigated the relationship between each

119 kinematic parameter and visual acuity to better understand the links between visual acuity of

120 pathology in motor performance. Indeed, kinematic parameters are known to be influenced by

121 visual acuity. ${ }^{12,20,27}$

\section{Methods}

124 Participants

125 Sixteen patients with primary open angle glaucoma (POAG) were recruited in the

126 ophthalmology department of Claude Huriez Hospital, Lille, France. All participants

127 underwent SITA-standard 30-2 perimetry with a Humphrey Visual Field Analyzer II (HFA,

128 Carl Zeiss Meditec, Dublin, CA, USA), had glaucoma-related visual field (VF) defects and a

129 mean deviation (MD) worse or equal to $-6 \mathrm{~dB}$ (SITA-standard 30-2: $\mathrm{MD}=-16.4 \pm \mathrm{SD}=5.76$; 
range: 8.6 - 27). They had to have a monocular visual acuity of $6 / 12$ or more in the tested eye

131 (best eye included in the recruitment criteria). If both eyes had equal acuity, one eye was

132 randomly selected.

133 There were 14 volunteers with normal visual acuity among the age-matched

134 participants. They were either relatives of participants with glaucoma or patients who had

135 undergone successful cataract surgery, with normal visual acuity ranging from 20/25 to 20/20.

136 Age-matched participants were recruited in the ophthalmology department of Claude Huriez

137 Hospital, Lille, France. Controls were tested monocularly on their preferred eye. A young

138 adult group included 18 healthy students (in medicine, neuroscience and psychology) with

139 normal vision (visual acuity $=20 / 20$ ). Young people were included as controls to dissociate

140 the effect of ageing from the effect of pathology. All participants had one eye patched (the eye

141 with lower acuity for patients). Demographic data are provided in Table 1. Clinical data are 142 provided in Table 2.

143

144

145

146

147

148

149

150

151

152

153

47

48

/ Insert table 1 here /

/ Insert table 2 here /

participants. Participants with a history of neurological disease, psychiatric disease, cognitive impairment $(\mathrm{MMSE}<25 / 30)$ or other ocular diseases (cataract, AMD) that might compromise oculomotor function were excluded. A physical therapist tested the participants for normal motion of the right arm and hand. All participants were right-handed. The study was approved by the ethics committee of Lille University. In accordance with the tenets of the Declaration of Helsinki, written informed consent was obtained from all participants. 


\section{Apparatus and material}

Participants sat in front of a table $(120 \times 80 \mathrm{~cm})$ and placed their thumb and index close to a starting point located $10 \mathrm{~cm}$ from the edge of the table (see Figure 1). Five cylinders (height: $10.5 \mathrm{~cm}$, diameter: $5.5 \mathrm{~cm}$ ) located on the table in a semi-circle (radius: $25 \mathrm{~cm}$ from the starting point) at $0^{\circ}$ (center), $30^{\circ}$ and $60^{\circ}$ to the left and the right of the center cylinder were used as stimuli. The participants' head was positioned $60 \mathrm{~cm}$ from the central cylinder. All cylinders positioned on the table were the same color (wood color). Before each trial, they were (re)positioned in these five precise locations by the experimenter. In front of the table, a curved screen $\left(180^{\circ}\right.$ degrees of eccentricity) displayed the different steps of each trial (fixation cross, five colored cylinders at five spatial locations, Figure 1). Participants performed two tasks in a random order: one with a temporal constraint for visual exploration (immediate condition) and one with no temporal constraint for visual exploration (delayed condition). Each condition involved 25 trials determined by five colors (blue; red; yellow; white; black $)^{*}$ five spatial locations $\left(60^{\circ}\right.$ right; $30^{\circ}$ right; $0^{\circ} ; 30^{\circ}$ left; $60^{\circ}$ left $)$. A schematic representation of both tasks is shown in Figure 2. Before the experiment, each color cylinder was displayed and the participants had to recognize each color. All participants were able to name the colors of the five cylinders.

/Insert figure 1 here /

/Insert figure 2 here /

In the task with a temporal constraint for visual exploration (immediate condition), participants placed their thumb and index on the starting point and looked at the fixation cross displayed on the curved screen. Simultaneously, the name of a color was given by a 
180 loudspeaker $2000 \mathrm{~ms}+/-500 \mathrm{~ms}$ and five colored cylinders were displayed on the curved 181 screen in five different spatial locations $\left(0^{\circ}\right.$ center, $30^{\circ}$ left and right and $60^{\circ}$ left and right).

182 The colored cylinders and the spatial locations on the screen were changed randomly between

183 participants and trials. Participants explored the displayed colored cylinders. As soon as they recognized the spatial location of the given color, the participants were instructed to reach and grasp as quickly and accurately as possible the cylinder on the table with the corresponding color. They were asked to lift it approximately $10 \mathrm{~cm}$, put it on the table and return to the starting point.

In the task with no temporal constraint for visual exploration (delayed condition), the same procedure was used, except that participants were not to reach and grasp the cylinder as soon as they recognized the target color but only after an auditory cue. Participants placed their thumb and index on the starting point and then fixated the cross displayed on the curved screen. Simultaneously, a color was given by a loudspeaker $2000 \mathrm{~ms}+/-500 \mathrm{~ms}$ and colored cylinders were displayed on the curved screen in five spatial locations $\left(0^{\circ}, 30^{\circ}\right.$ left and right and $60^{\circ}$ left and right). The colored cylinders and spatial locations on the screen were changed randomly between participants and trials. Participants explored the displayed colored cylinders. Unlike in the immediate condition, participants had to wait for an auditory cue to reach and grasp the cylinder corresponding to the given color as quickly and accurately as possible. This cue occurred $2000 \mathrm{~ms}+/-500 \mathrm{~ms}$ after the color was given. The time between the color name and the auditory cue allowed the exploration of the displayed cylinders. In this condition, the participants had time to identify the target cylinder and to prepare their reachand-grasp movement. As soon as they heard the auditory cue, they had to reach and grasp the cylinder as quickly and accurately as possible, lift it approximately $10 \mathrm{~cm}$, put it on the table and return to the starting point. 


\section{Data Recording and Analysis}

A magnetic tracking system (Polhemus Liberty 240/8-8 System, Colchester, VT) was used to record the participants' movements in a $\mathrm{X}, \mathrm{Y}$ and $\mathrm{Z}$ coordinates system. The

kinematics of the reach-and-grasp movements and cylinder displacements were measured by

210 eight markers that were placed on the index (base and tip), the thumb (tip), and the wrist

211 (scaphoid and pisiform) of the participants. One additional marker was placed on each of the

212 five cylinders. The spatial environment (table and cylinder) was calibrated before each

213 session, allowing the system to reach a temporal and spatial resolution accuracy lower than

$214 \quad 0.2 \mathrm{~mm}$ at a $240 \mathrm{~Hz}$ sampling rate.

All parameters were computed with a custom program (MatLab®; MathWorks®,

216 Natick) based on the 3D coordinates of the reflective marker placed on the wrist, index and

217 thumb of the participants and on the five markers on the cylinders. The kinematic outcome

218 measures were computed on the basis of the wrist marker. Temporal and kinematic

219 parameters of the $(\mathrm{x}, \mathrm{y}, \mathrm{z})$ coordinates of the wrist marker were computed from tangential

220 velocity profiles, after filtering the data using a second-order Butterworth dual-pass filter (cut-

221 off frequency: $15 \mathrm{~Hz}$ ). Movement onset was defined as the first velocity value reaching 0.3

$222 \mathrm{~cm} / \mathrm{s}$.

The following kinematic parameters of the reach-and-grasp trajectories were 225 calculated (Figure 3):

1. "Movement duration" corresponding to the time between movement onset and movement end (defined as the moment when participants reached the cylinder). 
3. "Acceleration interval" corresponding to the time between the onset of hand 231 movement and the "peak velocity" moment.

4. "Deceleration interval" corresponding to the time between "peak velocity" moment and the end of the movement.

5. "Maximum grip aperture" (MGA) corresponding to the maximum distance between thumb and index during movement.

6. "Time to maximum grip aperture" corresponding to the time between the onset of hand movement and the time of maximum grip aperture.

Trials were excluded from the data analysis when a participant responded erroneously. $1.6 \%$ of the trials, homogenously distributed across the conditions, were discarded. For each task, a $2 \times 3$ analysis of variance was conducted with each group \{Glaucoma patients; Agematched Controls; Young Controls \} as the between-participants factor and angle condition $\left\{0^{\circ} ; 30^{\circ}\right.$ right; $30^{\circ}$ left; $60^{\circ}$ right; $60^{\circ}$ left $\}$ as the within-participants factor. Local comparisons were performed using a post-hoc Bonferroni test with threshold corrections, in order to account for multiple group factor comparisons and possible interactions between Group and Angle. For the sake of clarity, principal effect of angle and post-hoc are not presented because we had no hypothesis on this factor. Spearman correlations for glaucoma patients were computed between each kinematic parameter, visual acuity, MD 30-2 and

251 duration of pathology. Finally, comparisons of the results of the immediate condition vs 3,4 and 5. 


\section{Movement duration}

A group effect was observed on movement durations $\left(\mathrm{F}_{(2,45)}=36.5 ; p<0.001 ; \eta^{2}=\right.$ 0.6). The movement duration of glaucoma patients $\left(X_{\text {mean }}=1179 \mathrm{~ms} ; \mathrm{SD}=250 \mathrm{~ms}\right)$ was significantly longer than that of age-matched participants $\left(X_{\text {mean }}=1001.8 \mathrm{~ms} ; \mathrm{SD}=169.6 \mathrm{~ms}\right.$; $\mathrm{p}<0.014)$ and young participants $\left(\mathrm{X}_{\text {mean }}=680.2 \mathrm{~ms} ; \mathrm{SD}=106.5 \mathrm{~ms} ; \mathrm{p}<0.001\right)$. The movement duration of age-matched participants was significantly longer than that of young participants $(\mathrm{p}<0.001)$

\section{Peak velocity}

A group effect was observed on peak velocity $\left(\mathrm{F}_{(2,45)}=11.6 ; p<0.001 ; \eta^{2}=0.27\right)$.

Peak velocity of glaucoma patients $\left(X_{\text {mean }}=32.4 \mathrm{~cm} / \mathrm{s} ; \mathrm{SD}=10.2 \mathrm{~cm} / \mathrm{s}\right)$ was significantly faster than peak velocity of age-matched participants $\left(X_{\text {mean }}=24.4 \mathrm{~cm} / \mathrm{s} ; \mathrm{SD}=7.4 \mathrm{~cm} / \mathrm{s} ; \mathrm{p}=\right.$ $0.002)$ and young participants $\left(X_{\text {mean }}=22.8 \mathrm{~cm} / \mathrm{s} ; \mathrm{SD}=2.4 \mathrm{~cm} / \mathrm{s} ; \mathrm{p}<0.001\right)$. No significant difference was found between age-matched and young participants. $=0.032 ; \eta^{2}=0.016 ;$ Figure 4). The Bonferroni post-hoc comparison revealed that peak velocity for glaucoma patients was faster than peak velocity for age-matched participants and young participants, only at $60^{\circ}$ eccentricity on the left (respectively $p=0.05$ and $p=0.002$ ) and right angles (respectively $\mathrm{p}=0.007$ and $\mathrm{p}<0.001$ ). 
A group effect was observed on the acceleration interval $\left(\mathrm{F}_{(2,45)}=12.7 ; p<0.001 ; \eta^{2}=\right.$

0.27). The acceleration interval of glaucoma patients $\left(X_{\text {mean }}=358.4 \mathrm{~ms} ; \mathrm{SD}=107 \mathrm{~ms} ; \mathrm{p}<\right.$

$0.001)$ and age-matched participants $\left(\mathrm{X}_{\text {mean }}=378.2 \mathrm{~ms} ; \mathrm{SD}=82.7 \mathrm{~ms} ; \mathrm{p}<0.001\right)$ was significantly longer than that of young participants $\left(X_{\text {mean }}=269.4 \mathrm{~ms} ; \mathrm{SD}=55 \mathrm{~ms}\right)$.

No interaction was found between group and angle on acceleration intervals.

A group effect was observed on the deceleration interval $\left(\mathrm{F}_{(2,45)}=28 ; p<0.001 ; \eta^{2}=\right.$

0.52). No difference was observed between glaucoma patients and age-matched participants.

The deceleration interval of both glaucoma patients $\left(X_{\text {mean }}=860.4 \mathrm{~ms} ; \mathrm{SD}=230 \mathrm{~ms} ; \mathrm{p}<\right.$ $0.001)$ and age-matched participants $\left(\mathrm{X}_{\text {mean }}=760.4 \mathrm{~ms} ; \mathrm{SD}=139 \mathrm{~ms} ; \mathrm{p}<0.001\right)$ was significantly longer than that of young participants $\left(X_{\text {mean }}=458.6 \mathrm{~ms} ; \mathrm{SD}=129.8 \mathrm{~ms}\right)$.

$\left.297=4.53 ; \mathrm{p}<0.001 ; \eta^{2}=0.014\right)$. The Bonferroni post-hoc comparison revealed differences for 298 glaucoma patients and age-matched participants in comparison to young participants ( $\mathrm{p}$ 299 0.001) for all angles (except young versus age-matched participants for $60^{\circ}$ right $(\mathrm{p}=0.02)$ 300 and $60^{\circ}$ left $\left.(\mathrm{p}=0.003)\right)$. 
No group effect was observed on maximum grip aperture. Maximum grip aperture of 304 glaucoma patients $\left(X_{\text {mean }}=8.96 \mathrm{~cm} ; \mathrm{SD}=1.82 \mathrm{~cm}\right)$ was not significantly different from the maximum grip aperture of age-matched participants $\left(\mathrm{X}_{\text {mean }}=8.88 \mathrm{~cm} ; \mathrm{SD}=1.04 \mathrm{~cm}\right)$ and young participants $\left(X_{\text {mean }}=9.47 \mathrm{~cm} ; \mathrm{SD}=1.09 \mathrm{~cm}\right)$.

An interaction was found between group and angle on maximum grip aperture $\left(\mathrm{F}_{(8,180)}\right.$ $\left.=1.21 ; p=0.03 ; \eta^{2}=0.017\right)$. The Bonferroni post-hoc comparison revealed a difference between $60^{\circ}$ right $\left(\mathrm{X}_{\text {mean }}=8.62 \mathrm{~cm} ; \mathrm{SD}=2.38 \mathrm{~cm}\right)$ and $60^{\circ}$ left $\left(\mathrm{X}_{\text {mean }}=9.31 \mathrm{~cm} ; \mathrm{SD}=1.87\right.$ $\mathrm{cm})$ for glaucoma patients only $(\mathrm{p}=0.034)$.

\section{Time to maximum grip aperture}

A group effect was observed on time to maximum grip aperture $\left(\mathrm{F}_{(2,45)}=23.7\right.$; $p<$ $\left.0.001 ; \eta^{2}=0.42\right)$. The time to maximum grip aperture of glaucoma patients $\left(X_{\text {mean }}=716.4 \mathrm{~ms}\right.$; $\mathrm{SD}=191 \mathrm{~ms} ; \mathrm{p}<0.001)$ and age-matched participants $\left(\mathrm{X}_{\text {mean }}=665.4 ; \mathrm{SD}=98 \mathrm{~cm} ; \mathrm{p}>0.001\right)$ was significantly shorter than that of young participants $\left(X_{\text {mean }}=463.6 \mathrm{~cm} ; \mathrm{SD}=102.1 \mathrm{~cm}\right)$. No interaction was found between group and angle on time to maximum grip aperture.

Finally, correlations were found between visual acuity for glaucoma patients and 
suggesting a link between deficit intensity and deficit of movement kinematic parameters (Table 3 and Figure 5).

\section{/ Insert Figure 5 here /}

To summarize (Table 4), in the immediate condition, participants with glaucoma had significantly longer movement duration and higher peak velocity than age-matched and young participants. This result indicates an effect of glaucoma on the reaching phase of the movement. Interestingly, peak velocity for glaucoma patients was higher for cylinders located in the peripheral field of vision $\left(60^{\circ}\right.$ left and right angle), thus suggesting that the deficit in movement kinematics is related to the visual field deficit.

\section{/Insert Table 4 here /}

/Insert Table 5 here /

\section{Movement duration}

A group effect was observed on movement durations $\left(\mathrm{F}_{(2,45)}=41.4 ; p<0.001 ; \eta^{2}=\right.$ 0.63). The movement duration of glaucoma patients $\left(X_{\text {mean }}=1251.4 \mathrm{~ms} ; \mathrm{SD}=242.2 \mathrm{~ms}\right)$ was significantly longer than that of age-matched participants $\left(\mathrm{X}_{\text {mean }}=1066 \mathrm{~ms} ; \mathrm{SD}=175 \mathrm{~ms} ; \mathrm{p}=\right.$ $0.02)$ and young participants $\left(X_{\text {mean }}=716 \mathrm{~ms} ; \mathrm{SD}=110.8 \mathrm{~ms} ; \mathrm{p}<0.001\right)$. The movement duration of age-matched participants was significantly longer than that of young participants, $\mathrm{p}<0.001)$ 
An interaction was found between Group and Angle on movement duration $\left(\mathrm{F}_{(8,180)}=\right.$ 2.99; $\left.p=0.004 ; \eta^{2}=0.006\right)$. No significant differences were observed between the movement 351 duration of glaucoma patients and age-matched participants for all angles. The movement 352 duration of glaucoma patients and age-matched participants was significantly longer than that 353 of young participants ( $\mathrm{p}<0.01$ for all angles, except age-matched versus young participants at $35460^{\circ}$ left $\left.(\mathrm{p}=0.007)\right)$.

\section{Peak velocity}

A group effect was observed on peak velocity $\left(\mathrm{F}_{(2,45)}=5.06 ; p=0.01 ; \eta^{2}=0.108\right)$.

Peak velocity of both glaucoma patients $\left(X_{\text {mean }}=39.2 \mathrm{~cm} / \mathrm{s} ; \mathrm{SD}=11.7 \mathrm{~cm} / \mathrm{s}\right)$ and age-matched participants $\left(X_{\text {mean }}=40.1 \mathrm{~cm} / \mathrm{s} ; \mathrm{SD}=10.7 \mathrm{~cm} / \mathrm{s}\right)$ was significantly faster than that of young participants $\left(\mathrm{X}_{\text {mean }}=32.9 \mathrm{~cm} / \mathrm{s} ; \mathrm{SD}=5.3 \mathrm{~cm} / \mathrm{s}\right.$; respectively $\mathrm{p}=0.05$ and $\left.\mathrm{p}=0.02\right)$.

No interaction was found between group and angle on peak velocity.

\section{Acceleration interval}

A group effect was observed on the acceleration interval $\left(\mathrm{F}_{(2,45)}=6.03 ; p=0.005 ; \eta^{2}=\right.$

0.157). The acceleration interval of glaucoma patients $\left(X_{\text {mean }}=390.8 \mathrm{~ms} ; \mathrm{SD}=100.6 \mathrm{~ms} ; \mathrm{p}=\right.$ 0.06 (trend) $)$ and age-matched participants $\left(\mathrm{X}_{\text {mean }}=413 \mathrm{~ms} ; \mathrm{SD}=109.6 \mathrm{~ms} ; \mathrm{p}=0.006\right)$ was significantly longer than that of young participants $\left(X_{\text {mean }}=327 \mathrm{~ms} ; \mathrm{SD}=42.1 \mathrm{~ms}\right)$. 
3.34; $\left.p=0.001 ; \eta^{2}=0.036\right)$. The Bonferroni post-hoc comparison revealed a difference

\section{Deceleration interval}

A group effect was observed on the deceleration interval $\left(\mathrm{F}_{(2,45)}=59.2 ; p<0.001 ; \eta^{2}=\right.$

0.704). The deceleration interval of glaucoma patients $\left(X_{\text {mean }}=860.4 \mathrm{~ms} ; \mathrm{SD}=162.8 \mathrm{~ms} ; \mathrm{p}<\right.$

0.001) was longer than that of age-matched participants $\left(X_{\text {mean }}=651.6 \mathrm{~ms} ; \mathrm{SD}=138 \mathrm{~ms} ; \mathrm{p}<\right.$ $0.001)$ and young participants $\left(X_{\text {mean }}=389.4 \mathrm{~ms}\right.$; $\left.\mathrm{SD}=95.7 \mathrm{~ms}\right)$. The deceleration interval of age-matched participants was longer than that of young participants $(\mathrm{p}<0.001)$.

No interaction was observed between group and angle.

\section{Maximum grip aperture}

A group effect was observed on maximum grip aperture $\left(\mathrm{F}_{(2,45)}=3.5 ; p<0.04 ; \eta^{2}=\right.$

0.13). The maximum grip aperture of glaucoma patients $\left(X_{\text {mean }}=8.7 \mathrm{~cm}\right.$; $\left.S D=1.4 \mathrm{~cm}\right)$ was not significantly different from that of age-matched participants $\left(X_{\text {mean }}=8.8 \mathrm{~cm} ; \mathrm{SD}=1 \mathrm{~cm}\right)$.

A tendency was observed between the maximum grip aperture of glaucoma patients and that of young participants $(\mathrm{p}=0.079) .\left(\mathrm{X}_{\text {mean }}=9.6 \mathrm{~cm} ; \mathrm{SD}=1 \mathrm{~cm}, \mathrm{p}=0.08\right)$.

No interaction was found between group and angle on maximum grip aperture. 
A group effect was observed on time to maximum grip aperture $\left(\mathrm{F}_{(2,45)}=19.2 ; p<\right.$

$\left.3940.001 ; \eta^{2}=0.29\right)$. A Bonferroni post-hoc comparison revealed a significant interaction 395 between the time to maximum grip aperture of both glaucoma patients $\left(\mathrm{X}_{\text {mean }}=804.2 \mathrm{~ms}\right.$; SD $396=253.2 \mathrm{~ms})$ and age-matched participants $\left(\mathrm{X}_{\text {mean }}=727 ; \mathrm{SD}=148 \mathrm{~cm}\right)$ with young 397 participants $\left(X_{\text {mean }}=496.8 \mathrm{~cm} ; \mathrm{SD}=86.1 \mathrm{~cm}, \mathrm{p}<0.001\right)$.

No interaction was found between group and angle on time to maximum grip aperture.

400

401

Finally, no correlation was found between visual acuity and kinematics parameters for 402 glaucoma patients.

403

404

To summarize (Table 5), in the delayed condition, glaucoma patients had significantly longer movement duration and deceleration interval than age-matched and young participants.

This result indicates an effect of glaucoma on the grasping phase of the movement. Interestingly, the deceleration deficit in glaucoma patients was not affected by the location of 408 the cylinder, suggesting that it does not depend on the location of the visual field deficit.

patient

No statistical difference was observed between immediate and delayed tasks for each

413 glaucoma patient on movement durations, deceleration interval, maximum grip aperture and 414 time to maximum grip aperture. 
A statistical difference was observed between immediate and delayed task for 417 glaucoma patient on peak velocity $\left(\mathrm{F}_{(1,14)}=6.04 ; p=0.032 ; \eta^{2}=0.07\right)$ and acceleration 418 interval $\left(\mathrm{F}_{(1,14)}=4,87 ; p=0.05 ; \eta^{2}=0.023\right)$. Glaucoma patient had faster peak velocity in delayed task $\left(X_{\text {mean }}=39.2 \mathrm{~cm} / \mathrm{s} ; \mathrm{SD}=11.7 \mathrm{~cm} / \mathrm{s}\right)$ than in immediate task $\left(X_{\text {mean }}=32.4 \mathrm{~cm} / \mathrm{s}\right.$; $\mathrm{SD}=10.2 \mathrm{~cm} / \mathrm{s})$. Glaucoma patient had longer acceleration interval in delayed task $\left(\mathrm{X}_{\text {mean }}=\right.$ $390.8 \mathrm{~ms} ; \mathrm{SD}=100.6 \mathrm{~ms})$ than in immediate task $\left(\mathrm{X}_{\text {mean }}=358.4 \mathrm{~ms} ; \mathrm{SD}=107 \mathrm{~ms}\right)$

\section{Discussion}

The present study was designed to investigate whether abnormalities in reach-andgrasp tasks observed in previous studies in glaucoma patients resulted from difficulties in the perception of the relevant metric parameters to reach and grasp a target object (immediate condition: no time for visual exploration) or in motor production (delayed condition: time for visual exploration). Glaucoma patients and age-matched participants differed significantly in movement duration and peak velocity when participants had a temporal constraint for visual exploration (immediate condition). Glaucoma patients exhibited faster peak velocity, which is related to the reaching phase of the motor action execution. ${ }^{29,30}$ Comparison of the immediate condition $\left(\mathrm{X}_{\text {mean }}=32.4 \mathrm{~cm} / \mathrm{s} ; \mathrm{SD}=10.2 \mathrm{~cm} / \mathrm{s}\right)$ versus the delayed condition $\left(\mathrm{X}_{\text {mean }}=39.2\right.$ $\mathrm{cm} / \mathrm{s} ; \mathrm{SD}=11.7 \mathrm{~cm} / \mathrm{s}$ ) for each glaucoma patient confirm statistical difference on peak velocity. Moreover, a positive correlation was found for the immediate condition between the visual acuity of glaucoma patients and both movement duration and deceleration interval for all angles and time to MGA at $60^{\circ}$ left angle. These results are consistent with previous

437 studies showing a longer movement duration and correlations between visual acuity and both 438 movement duration and peak velocity in glaucoma patients. ${ }^{20}$ However, Kotecha and al. 439 (2009) reported a negative correlation between visual acuity and peak velocity. One 440 explanation could be that the participants' strategy consists in faster peak velocity to avoid the 
acceleration interval (and movement duration) as "normal". Consistent with this explanation,

442 we found no difference in terms of acceleration interval between glaucoma patients and age443 matched participants, unlike Kotecha et al. (2009). Methodological differences could account 444 for this change in strategy. In our study, the cylinders had the same size $(5.5 \mathrm{~cm})$ and 445 locations $(25 \mathrm{~cm})$ from the starting point at 0 (center), $30^{\circ}$ and $60^{\circ}$ to the left and to the right 446 of the central cylinder. In the studies by Kotecha et al., the cylinder changed in size ( 24 or 48 $447 \mathrm{~mm}$ ) and spatial location (200 $\mathrm{mm}$ or $400 \mathrm{~mm}$ ) at each trial. Therefore, in their study, the 448 participants had to adjust the maximum opening of their hand to the size of the object, 449 whereas this adaptation was not required in our study because all cylinders had the same size 450 and distance. Participants can use the "same" motor command to adjust their maximum grip 451 aperture at each trial. ${ }^{22,23}$ Interestingly, peak velocity differed between glaucoma patients and 452 age-matched participants, especially at $60^{\circ}$ eccentricity left and right. Even though the 453 participants were in a natural situation where they could move their head freely, the deficit in the peripheral visual field of glaucoma patients affected their kinematic parameters, especially for an object located in the peripheral visual field.

As mentioned in the introduction, two interpretations might account for these differences: (1) the kinematic difference of patients' motor execution might result from the effect of visual impairment on motor production; or (2) the effect of visual impairment on identification (i.e., the spatial location and/or the width of the target) might lead to a motor deficit. To dissociate these hypotheses, a second task (the delayed condition) was proposed to 461 the same participants. In this task, participants had time to explore and identify the target and 462 the distractors before reaching and grasping the target. In the delayed condition, a significant 463 difference was found in kinematic parameters between glaucoma patients and aging controls.

464 These deficits were found in deceleration intervals, which correspond to the grasp phase and 465 online control of action. ${ }^{20,31,32}$ These result became clear in the light of the comparison 
466 between the performance in the immediate condition versus the delayed condition for each 467 glaucoma patient. The comparison revealed no statistical difference for the deceleration 468 interval $($ Xmean $=860.4 ; \mathrm{SD}=230 \mathrm{~ms}$ for immediate condition and Xmean $=860.4 \mathrm{~ms} ; \mathrm{SD}$ $469=162.8 \mathrm{~ms}$ for delayed condition). Hence, time to exploration is not helpful for glaucoma 470 patient. The difference in the delayed condition on deceleration interval between glaucoma 471 patient $($ Xmean $=860.4 \mathrm{~ms} ; \mathrm{SD}=162.8 \mathrm{~ms})$ and age-matched participant $($ Xmean $=651.6$ $472 \mathrm{~ms} ; \mathrm{SD}=138 \mathrm{~ms}$ ) results from increase performance (i.e. faster deceleration interval) for 473 age-matched participant between the delayed condition (Xmean $=651.6 \mathrm{~ms} ; \mathrm{SD}=138 \mathrm{~ms}$ ) 474 and the immediate condition (Xmean $=760.4 \mathrm{~ms}$; SD $=139 \mathrm{~ms}$ ) indicating that time to visual 475 exploration is helpful for age-matched participant but not for glaucoma patient.

477 had no time to explore the visual scene (immediate condition). The deficit is specific to the reach phase. The motor abnormalities in reaching phase observed in glaucoma patient in previous studies seem to result from difficulties in target identification rather than from visuomotor deficits. Further studies are needed in binocular viewing conditions with various natural objects to confirm and clarify these results and extend them to daily life activities.

\section{Conclusion and limitations}

Glaucoma patients exhibited a motor disorder (reaching phase) in our study, only when they had no time to explore their environment before performing the reach-and-grasp task. From a clinical point of view, motor performance of glaucoma patients could be 


\section{References}

1. World Health Organization. Action plan for the prevention of avoidable blindness and visual impairment, 2009-2013. Published online 2010.

2. Glovinsky Y, Quigley HA, Dunkelberger GR. Retinal ganglion cell loss is size dependent in experimental glaucoma. Invest Ophthalmol Vis Sci. 1991;32(3):484-491.

3. Quigley HA, Dunkelberger GR, Green WR. Chronic Human Glaucoma Causing Selectively Greater Loss of Large Optic Nerve Fibers. Ophthalmology. 1988;95(3):357-363. doi:10.1016/S0161-6420(88)33176-3

4. Crabb DP, Smith ND, Glen FC, Burton R, Garway-Heath DF. How does glaucoma look?: patient perception of visual field loss. Ophthalmology. 2013;120(6):1120-1126. doi:10.1016/j.ophtha.2012.11.043

5. Dive S, Rouland JF, Lenoble Q, Szaffarczyk S, McKendrick AM, Boucart M. Impact of Peripheral Field Loss on the Execution of Natural Actions: A Study With Glaucomatous Patients and Normally Sighted People. doi:info:doi/10.1097/IJG.0000000000000402

6. Ramulu PY, West SK, Munoz B, Jampel HD, Friedman DS. Driving Cessation and Driving Limitation in Glaucoma: The Salisbury Eye Evaluation Project. Ophthalmology. 2009;116(10):1846-1853. doi:10.1016/j.ophtha.2009.03.033

7. González-Alvarez C, Subramanian A, Pardhan S. Reaching and grasping with restricted peripheral vision. Ophthalmic Physiol Opt J Br Coll Ophthalmic Opt Optom. 2007;27:265-274. doi:10.1111/j.1475-1313.2007.00476.x

8. Sivak B, MacKenzie CL. Integration of visual information and motor output in reaching and grasping: The contributions of peripheral and central vision. Neuropsychologia. 1990;28(10):1095-1116. doi:10.1016/00283932(90)90143-C

9. Ergun E, Maár N, Radner W, Barbazetto I, Schmidt-Erfurth U, Stur M. Scotoma size and reading speed in patients with subfoveal occult choroidal neovascularization in age-related macular degeneration. Ophthalmology. 2003;110(1):65-69. doi:10.1016/S0161-6420(02)01566-X

10. Rubin GS. Vision rehabilitation for patients with age-related macular degeneration. Eye. 2001;15(3):430-435. doi:10.1038/eye.2001.148

11. Tejeria L, Harper RA, Artes PH, Dickinson CM. Face recognition in age related macular degeneration: perceived disability, measured disability, and performance with a bioptic device. Br J Ophthalmol. 2002;86(9):1019-1026.

12. Pardhan S, Gonzalez-Alvarez C, Subramanian A. How does the presence and duration of central visual impairment affect reaching and grasping movements? Ophthalmic Physiol Opt. 2011;31(3):233-239. doi:10.1111/j.14751313.2010.00819.x

13. Timberlake GT, Omoscharka E, Quaney BM, Grose SA, Maino JH. Effect of bilateral macular scotomas from agerelated macular degeneration on reach-to-grasp hand movement. Invest Ophthalmol Vis Sci. 2011;52(5):2540-2550. doi:10.1167/iovs.10-6062

14. Connolly JD, Goodale MA. The role of visual feedback of hand position in the control of manual prehension. Exp Brain Res. 1999;125(3):281-286.

15. Jeannerod M. Intersegmental Coordination During Reaching at Natural Visual Objects. In: Long J, Baddeley A, eds. Attention and Performance IX. Lawrence Erlbaum Associates; 1981:153-169.

16. Lee Y-L, Crabtree CE, Norman JF, Bingham GP. Poor shape perception is the reason reaches-to-grasp are visually guided online. Percept Psychophys. 2008;70(6):1032-1046. doi:10.3758/PP.70.6.1032

17. Ma-Wyatt A, McKee SP. Visual information throughout a reach determines endpoint precision. Exp Brain Res. 2007;179(1):55-64. doi:10.1007/s00221-006-0767-1

18. Saunders JA, Knill DC. Humans use continuous visual feedback from the hand to control fast reaching movements. Exp Brain Res. 2003;152(3):341-352. doi:10.1007/s00221-003-1525-2

19. Pardhan S, Gonzalez-Alvarez C, Subramanian A, Chung STL. How Do Flanking Objects Affect Reaching and Grasping Behavior in Participants with Macular Disorders? Invest Ophthalmol Vis Sci. 2012;53(10):6687-6694. doi:10.1167/iovs.12-9821 
20. Kotecha A, O'Leary N, Melmoth D, Grant S, Crabb DP. The functional consequences of glaucoma for eye-hand coordination. Invest Ophthalmol Vis Sci. 2009;50(1):203-213. doi:10.1167/iovs.08-2496

21. Grant S, Melmoth DR, Morgan MJ, Finlay AL. Prehension Deficits in Amblyopia. Invest Ophthalmol Vis Sci. 2007;48(3):1139-1148. doi:10.1167/iovs.06-0976

22. Sabes PN. The planning and control of reaching movements. Curr Opin Neurobiol. 2000;10(6):740-746.

23. Wolpert DM, Kawato M. Multiple paired forward and inverse models for motor control. Neural Netw Off J Int Neural Netw Soc. 1998;11(7-8):1317-1329.

24. Khan MA, Franks IM, Elliott D, et al. Inferring online and offline processing of visual feedback in target-directed movements from kinematic data. Neurosci Biobehav Rev. 2006;30(8):1106-1121.

doi:10.1016/j.neubiorev.2006.05.002

25. Corveleyn X, Lenoble Q, Szaffarczyk S, Tran THC, Boucart M. What Is the Nature of the Reach and Grasp Deficit in Wet Age-related Macular Degeneration? Optom Vis Sci Off Publ Am Acad Optom. 2018;95(3):171-182. doi:10.1097/OPX.0000000000001189

26. Boucart M, Delerue C, Thibaut M, Szaffarczyk S, Hayhoe M, Tran THC. Impact of Wet Macular Degeneration on the Execution of Natural Actions. Invest Ophthalmol Vis Sci. 2015;56(11):6832-6838. doi:10.1167/iovs.15-16758

27. Pardhan S, Scarfe A, Bourne R, Timmis M. A Comparison of Reach-to-Grasp and Transport-to-Place Performance in Participants With Age-Related Macular Degeneration and Glaucoma. Invest Ophthalmol Vis Sci. 2017;58(3):15601569. doi:10.1167/iovs.16-20273

28. Folstein MF, Folstein SE, McHugh PR. "Mini-mental state". A practical method for grading the cognitive state of patients for the clinician. J Psychiatr Res. 1975;12(3):189-198.

29. Chieffi S, Gentilucci M. Coordination between the transport and the grasp components during prehension movements. Exp Brain Res. 1993;94(3):471-477.

30. Hommel B. Action control according to TEC (theory of event coding). Psychol Res PRPF. 2009;73(4):512-526. doi:10.1007/s00426-009-0234-2

31. Desmurget M, Epstein CM, Turner RS, Prablanc C, Alexander GE, Grafton ST. Role of the posterior parietal cortex in updating reaching movements to a visual target. Nat Neurosci. 1999;2(6):563-567. doi:10.1038/9219

32. Jeannerod M. Mental imagery in the motor context. Neuropsychologia. 1995;33(11):1419-1432. 


\section{Figure Legends}

Figure 1. Schematic representation of experimental design. $\mathrm{R}=\mathrm{Red} ; \mathrm{B}=\mathrm{Blue} ; \mathrm{Y}=$ Yellow ; $\mathrm{G}=$ Green ; $\mathrm{W}=$ White

Figure 2. Schematic representation of both tasks. The major difference is the separation of the visual exploration phase and the reach-and-grasp phase in the task, with no temporal constraint for visual exploration compared to mixing these two phases (visual exploration and reach-and-grasp) in the task with temporal constraints for visual exploration.

Figure 3. Plot of thumb and object velocity (left axis, dashed line) and grip aperture (right axis, solid line) versus time for one trial of immediate condition. MGA: Maximum Grip Aperture.

Figure 4. Peak velocity in function of angle for glaucoma patients (square), age-matched (diamond) and young participants (round) for immediate condition. Bars correspond to standard error.

Figure 5. Mean deceleration interval (all angles) in function of visual acuity (left panel) and MD 30-2 for tested eyes (right panel) for glaucoma patients. 
Table 1

\begin{tabular}{|c|c|c|c|}
\hline & $\begin{array}{c}\text { Glaucoma } \\
\text { patient }\end{array}$ & Age-matched & $\begin{array}{l}\text { Young } \\
\text { Control }\end{array}$ \\
\hline Age & $\begin{array}{c}62.9 \\
(7.74)\end{array}$ & $\begin{array}{c}62.1 \\
(10.4)\end{array}$ & $\begin{array}{c}25.9 \\
(4.09)\end{array}$ \\
\hline Gender & 10 female & 11 female & 13 female \\
\hline Tested eye & 7 right & 7 right & 11 right \\
\hline MD 30-2 & $-16.4(5.76)$ & NA & NA \\
\hline $\begin{array}{c}\text { VA } \\
\text { LogMAR }\end{array}$ & $\begin{array}{c}0.11 \\
(0.09)\end{array}$ & NA & NA \\
\hline MMSE & $\begin{array}{c}28.6 \\
(1.46)\end{array}$ & $\begin{array}{c}28.9 \\
(0.73)\end{array}$ & $29.7(0.461)$ \\
\hline
\end{tabular}

Table 1. Demographic data of glaucoma patients, age-matched controls and young control participants. Standard deviation indicated between brackets. Aged-matched had VA ranging from $20 / 25$ to $20 / 20$. 
Table 2

\begin{tabular}{cccccc}
$\begin{array}{c}\text { Number/Age/ } \\
\text { Gender }\end{array}$ & MMSE & $\begin{array}{c}\text { Tested } \\
\text { Eye }\end{array}$ & $\begin{array}{c}\text { VA } \\
\text { LogMAR }\end{array}$ & $\begin{array}{c}\text { MD 30-2 } \\
\text { (tested eye) }\end{array}$ & $\begin{array}{c}\text { MD } \\
30-2\end{array}$ \\
\hline \hline 1/62/F & 30 & RE & 0 & -21.9 & -26.17 \\
2/67/F & 28 & RE & 0.1 & -8.6 & -9.1 \\
$3 / 74 / F$ & 28 & RE & 0.1 & -22.5 & -22.8 \\
4/62/F & 30 & RE & 0.1 & -9.1 & -26.5 \\
5/60/F & 30 & RE & 0 & -16.2 & -11.2 \\
6/60/M & 30 & RE & 0.2 & -16.1 & -8.6 \\
$7 / 46 / M$ & 28 & RE & 0.1 & -15.6 & -17.4 \\
$8 / 69 / F$ & 29 & LE & 0.1 & -9.04 & -10.9 \\
9/74/F & 25 & LE & 0.1 & -20 & -17.5 \\
10/62/F & 29 & LE & 0.2 & -16.1 & -20.6 \\
$11 / 68 / F$ & 29 & LE & 0.2 & -9.8 & -14.5 \\
$12 / 67 / F$ & 26 & LE & 0 & -15.4 & -11.2 \\
$13 / 59 / M$ & 30 & LE & 0 & -25.6 & -28.9 \\
$14 / 68 / M$ & 29 & LE & 0.2 & -27 & -27.4 \\
$15 / 59 / M$ & 28 & LE & 0.3 & -14.1 & -17.8 \\
$16 / 49 / M$ & 28 & LE & 0 & -15.3 & -17.6 \\
\hline
\end{tabular}

Table 2. Demographic and clinical data of patients with glaucoma. $L E=$ left eye, $R E=$ right eye, MMSE $=$ Mini-mental state examination. 
Table 3

\begin{tabular}{c|ccccc} 
& $60^{\circ}$ left & $30^{\circ}$ left & $0^{\circ}$ & $30^{\circ}$ right & $60^{\circ}$ right \\
\hline \hline $\begin{array}{c}\text { Movement } \\
\text { duration }\end{array}$ & $\mathbf{0 . 7 8}$ & 0.46 & 0.64 & 0.53 & $\mathbf{0 . 5 9}$ \\
$\begin{array}{c}\text { Peak Velocity } \\
\begin{array}{c}\text { Acceleration } \\
\text { interval }\end{array}\end{array}$ & 0.3 & 0.07 & 0.01 & 0.05 & 0.145 \\
$\begin{array}{c}\text { Deceleration } \\
\text { interval }\end{array}$ & 0.4 & 0.08 & 0.15 & 0.02 & 0.34 \\
MGA & 0.8 & 0.58 & 0.57 & 0.6 & 0.57 \\
Time to MGA & 0.02 & 0.12 & 0.11 & 0.13 & 0.03 \\
& 0.7 & 0.39 & 0.36 & 0.23 & 0.16
\end{tabular}

Table 3. Spearman correlations between visual acuity and each kinematic parameter in immediate condition for glaucoma patients. Correlations in bold are statistically significative. MGA = Maximum grip aperture 
Table 4

\begin{tabular}{|c|c|c|c|c|c|c|}
\hline & $\begin{array}{c}\text { Mouvement } \\
\text { Duration in } \\
\text { ms }\end{array}$ & $\begin{array}{l}\text { Peak } \\
\text { velocity in } \\
\mathrm{cm} / \mathrm{s}\end{array}$ & $\begin{array}{l}\text { Acceleration } \\
\text { interval in ms }\end{array}$ & $\begin{array}{l}\text { Deceleration } \\
\text { interval in ms }\end{array}$ & $\begin{array}{l}\text { MGA in } \\
\mathrm{mm}\end{array}$ & $\begin{array}{l}\text { Time to } \\
\text { MGA in } \\
\text { ms }\end{array}$ \\
\hline $\begin{array}{c}\text { Glaucoma } \\
\text { patient }\end{array}$ & $\begin{array}{l}1179 \\
(250)\end{array}$ & $\begin{array}{c}32.4 \\
(10.2)\end{array}$ & $\begin{array}{l}358.4 \\
(107)\end{array}$ & $\begin{array}{l}860.4 \\
(230)\end{array}$ & $\begin{array}{c}8,96 \\
(1.82)\end{array}$ & $\begin{array}{l}716,4 \\
(191)\end{array}$ \\
\hline $\begin{array}{c}\text { Age- } \\
\text { matched }\end{array}$ & $\begin{array}{l}1001,8 \\
(169.6)\end{array}$ & $\begin{array}{l}24.4 \\
(7.4)\end{array}$ & $\begin{array}{l}378.2 \\
(82.7)\end{array}$ & $\begin{array}{l}760,4 \\
(139)\end{array}$ & $\begin{array}{c}8,88 \\
(1.04)\end{array}$ & $\begin{array}{c}665,4 \\
(98.02)\end{array}$ \\
\hline $\begin{array}{l}\text { Young } \\
\text { control }\end{array}$ & $\begin{array}{c}680.2 \\
(106.5)\end{array}$ & $\begin{array}{l}22.8 \\
(2.4)\end{array}$ & $\begin{array}{c}269.4 \\
(55)\end{array}$ & $\begin{array}{c}458.6 \\
(129.8)\end{array}$ & $\begin{array}{c}9.47 \\
(1.09)\end{array}$ & $\begin{array}{c}463.6 \\
(102.1)\end{array}$ \\
\hline $\begin{array}{l}\text { Group } \\
\text { effect }\end{array}$ & $\mathrm{p}<0.001^{*}$ & $\mathrm{p}<0.001^{*}$ & $\mathrm{p}<0.01$ & $p<0.001$ & $p=0.28$ & $\mathrm{p}<0.001$ \\
\hline $\begin{array}{l}\text { Group } \\
{ }^{*} \text { Angle } \\
\text { effect }\end{array}$ & $p=0.013+$ & $p=0.032^{*}$ & $p=0.59$ & $p<0.001$ & $P=0.03$ & $p=0.45$ \\
\hline
\end{tabular}

Table 4. For each kinematic parameter, mean and standard deviation for glaucoma patients, age-matched and young participants with statistical results as a function of Group and of Angle*Group in the immediate condition. Significant effects are in bold font. ${ }^{*}$ indicates difference between glaucoma patients and age-matched participants in post-hoc test ( $\mathrm{p}<$ 0.05). + indicates tendential difference between glaucoma patients and age-matched participants in post-hoc test $(\mathrm{p}<0.1) . \mathrm{ms}$ : millisecond, $\mathrm{mm}$ : millimeter, $\mathrm{cm} / \mathrm{s}$ : centimeter per second. 
Table 5

\begin{tabular}{|c|c|c|c|c|c|c|}
\hline & $\begin{array}{c}\text { Mouvement } \\
\text { Duration in } \\
\text { ms }\end{array}$ & $\begin{array}{c}\text { Peak } \\
\text { velocity in } \\
\mathrm{cm} / \mathrm{s}\end{array}$ & $\begin{array}{l}\text { Acceleration } \\
\text { Interval in ms }\end{array}$ & $\begin{array}{c}\text { Deceleration } \\
\text { interval in } \\
\text { ms }\end{array}$ & $\begin{array}{l}\text { MGA in } \\
\mathrm{mm}\end{array}$ & $\begin{array}{l}\text { Time to } \\
\text { MGA in } \\
\text { ms }\end{array}$ \\
\hline $\begin{array}{c}\text { Glaucoma } \\
\text { patient }\end{array}$ & $\begin{array}{l}1251.4 \\
(242,2\end{array}$ & $\begin{array}{c}39.2 \\
(11.7)\end{array}$ & $\begin{array}{c}390.8 \\
(100.6)\end{array}$ & $\begin{array}{c}860.4 \\
(162.8)\end{array}$ & $\begin{array}{c}8.7 \\
(1.4)\end{array}$ & $\begin{array}{c}804.2 \\
(253.2)\end{array}$ \\
\hline $\begin{array}{c}\text { Age- } \\
\text { matched }\end{array}$ & $\begin{array}{l}1066 \\
(175)\end{array}$ & $\begin{array}{c}40.1 \\
(10.7)\end{array}$ & $\begin{array}{c}413 \\
(109.6)\end{array}$ & $\begin{array}{l}651.6 \\
(138)\end{array}$ & $\begin{array}{l}8.8 \\
(1)\end{array}$ & $\begin{array}{c}727 \\
(148)\end{array}$ \\
\hline $\begin{array}{l}\text { Young } \\
\text { control }\end{array}$ & $\begin{array}{c}716 \\
(110.8)\end{array}$ & $\begin{array}{l}32.9 \\
(5.3)\end{array}$ & $\begin{array}{c}327 \\
(42.1)\end{array}$ & $\begin{array}{l}389.4 \\
(95.7)\end{array}$ & $\begin{array}{l}9.6 \\
(1)\end{array}$ & $\begin{array}{l}496.8 \\
(86.1)\end{array}$ \\
\hline $\begin{array}{l}\text { Group } \\
\text { effect }\end{array}$ & $p<0.001^{*}$ & $p=0.01$ & $p=0.005$ & $p<0.001^{*}$ & $p=0.04$ & $p<0.001$ \\
\hline $\begin{array}{l}\text { Group } \\
{ }^{\star A n g l e ~} \\
\text { effect }\end{array}$ & $p=0.004$ & $p=0.097$ & $p=0.001$ & $p=0.103$ & $p=0.13$ & $p=0.6$ \\
\hline
\end{tabular}

Table 5. For each kinematic parameter, mean and standard deviation for glaucoma patients, age-matched and young participants with statistical results as a function of Group and of Angle*Group in the delayed condition. Significant effects are in bold font. * indicates difference between glaucoma patients and age-matched participants in post-hoc test ( $\mathrm{p}<$ 0.05). ms: millisecond, mm: millimeter, $\mathrm{cm} / \mathrm{s}$ : centimeter per second. 
Figure 1

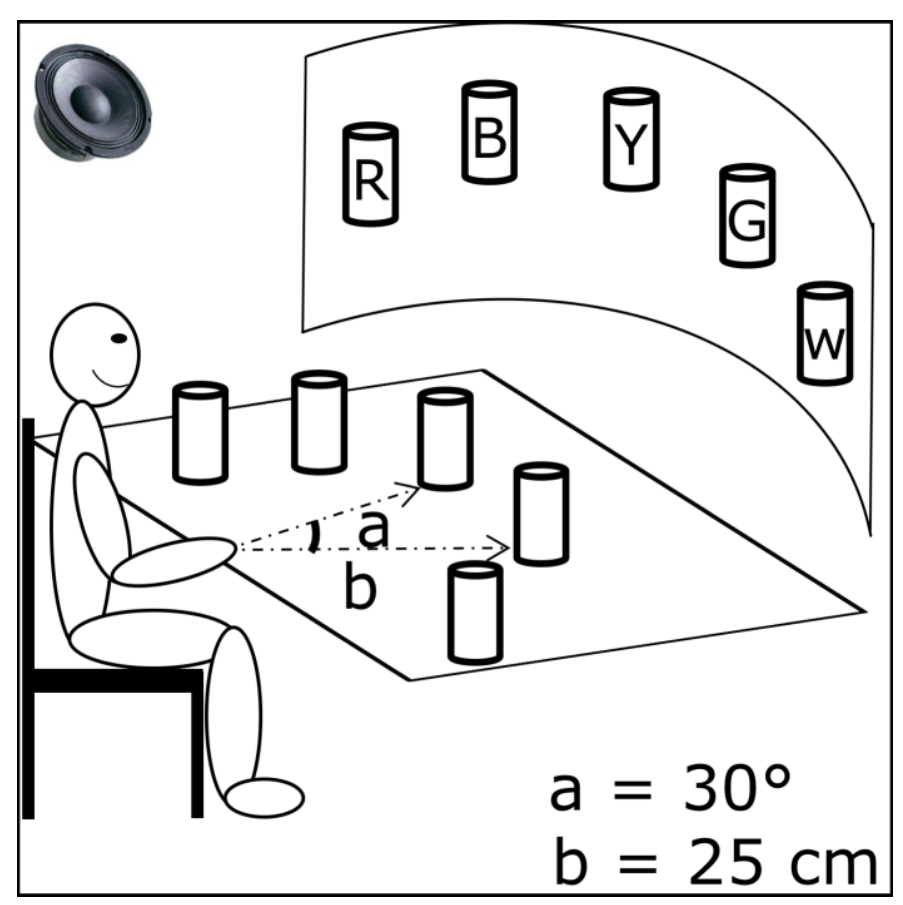


Figure 2

Task with no temporal constraint for visual exploration (Delayed condition):

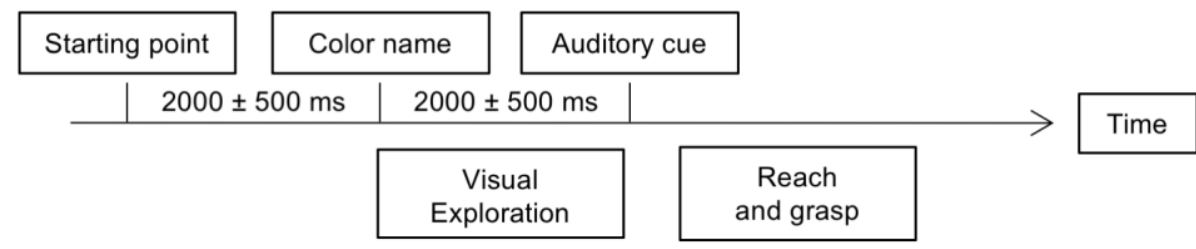

Task with temporal constraints for visual exploration (Immediate condition):

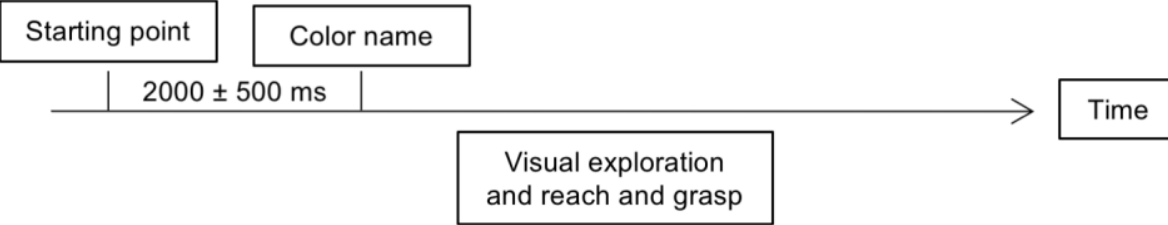

